\title{
The Care of Time
}

\author{
SCOTT POOLE \\ Virginia Polytechnic Institute and State University \\ USA
}

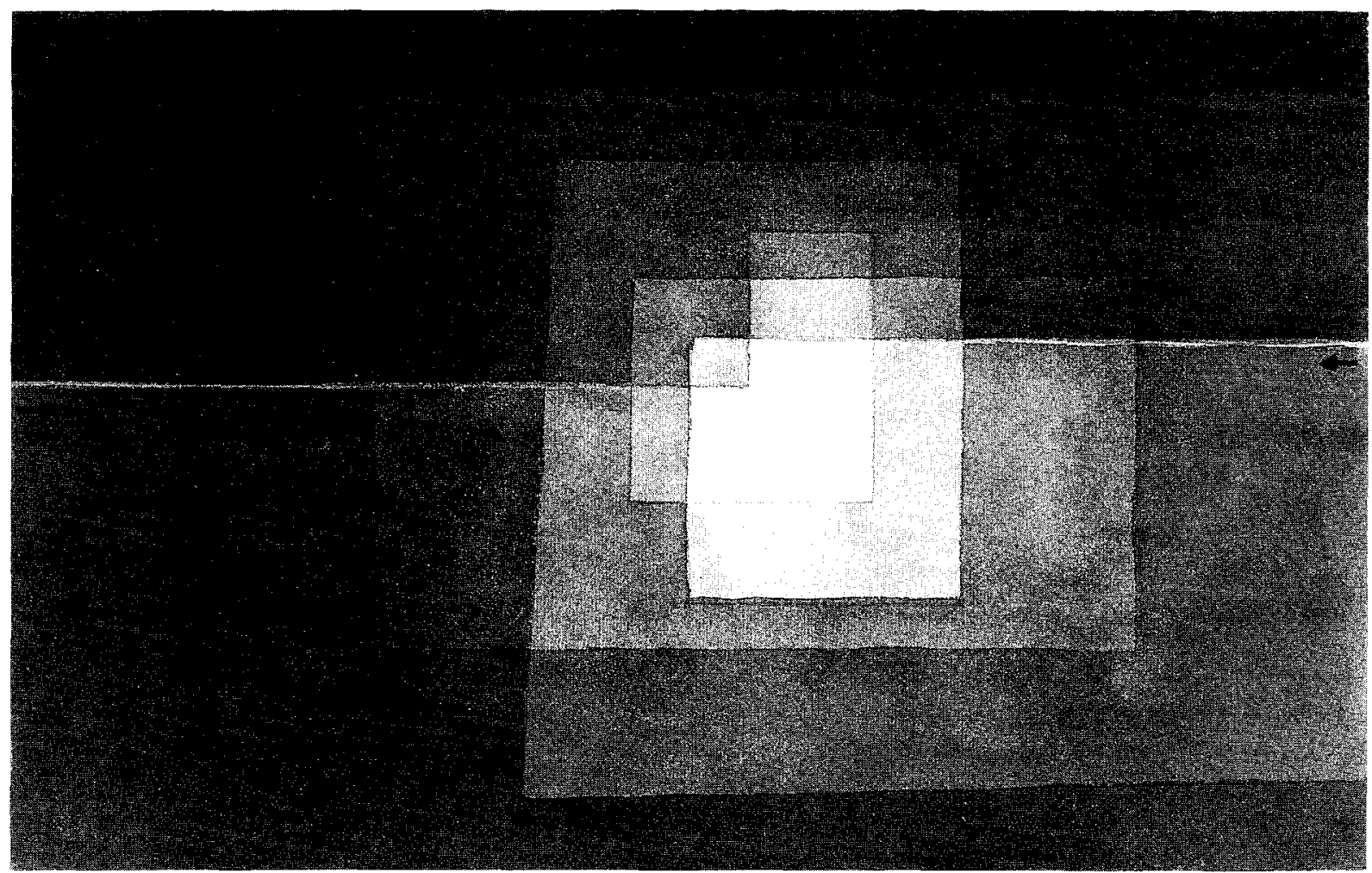

Fig. 1 Two Ways (Zwei Gänge), 1932, Black watercolor on paper, mounted on paper

\section{THE URGENCY OF EXISTENCE}

An aspect of contemporary life, which appears to be growing as this century comes to a close, is an obsessive urgency in the present. Images of speed from the world of technology dominate our consciousness and suggest, by implication, that haste itself is basic to human existence. 'Velocity,' it seems, is the dominant and foregone conclusion.

One could argue that this mode of existence, in which a person's relation to time is often agitated, restless, fast, and almost exclusively quantitative and chronological, diminishes the present and degrades the significance of time. To be sure, existence is urgent. After all, the time that we live is the only time that we have. But, do we have our time when every action has a materialistic motive, when each moment is measured by a quantity, and all of the present is anxious and uncertain? Do we have our time if, when time passes and 
nothing happens, we always feel uneasy? And do we really have our time if it is driven by an autonomous urgency detached from a purpose?

Paradoxically, we are losing the significance of the moment by a one-dimensional obsession with the present. In a present filled with agitated motion and indifferent to the whole of time, the moment, which is already elusive, lacks duration and presence; it becomes flat, shallow and dull. In this present, a person can find themselves absent from their own existence, detached from a desire to contemplate anything beyond the surface of life.

\section{THE SENSATION OF TIME}

Art contemplates ideas such as time. Because of this, it has the capacity to expand the horizon of the present by intensifying the moment and extending its backward and forward reach. In this present, moments are isolated by texture and depth, and the instant lacks neither brilliance nor intensity. In the extended duration of this present, time is maintained as an elusive quality, a metaphysical reality, that emerges from matter to evoke questions of being and the mystery of existence.

There is a room in a church in southwestern Sweden where a drop of water from a baptismal font extends a moment in order to indicate the presence of a reality beyond appearance. The acoustic pressure from this drop of water, slowly and repeatedly falling, disturbing the silence for an instant, separates this room from its lifeless state, with a moment of vitality. Each time the water falls, the brick room pulsates. Again and again, in the dim light and concentrated darkness, a percussive sound delineates an interval of motion and shapes the emptiness of the room. The presence of the sound is here and now; direct, immediate, and recurrent. It draws a person toward its cause: an object that holds water and a breach in the floor. With a sure and simple movement, the object takes possession of the space. It performs the work of a primordial instrument that measures the existential consequence of an event and a repetition.

What is ascertained by each falling drop is the particular hollowness of the room and the capacity of resonance to make moments thick with the present, dense with time. In this place, where time is almost tangible, the silence of a drop falling in a void separates forming and finality. It brings to mind the indeterminacy that separates birth and death and by continuously returning, the event distinguishes the temporality of an individual existence from the permanence of life.

The sensation of time can touch the very depth of our being. Unseen, it changes everything we see. The remains of time that appear on the surface of objects are capable of arousing strong emotions because of their proximity to the essence of human existence. With compelling clarity, a simple thing, like a tarnished silver cup, can help a person remember who they were and remind them what they are; a being conscious of time.

Many artists have made time essential to their work. Paul
Klee, for example, thought of the human being as a "timepiece built of blood." In his watercolors, layering tone upon tone was a way to measure time. By artistic means, the before and after of this sequential development of surface is transformed from then and now, to only now - to the simultaneity of a moment in the present. Looking at these paintings is like cutting a section through a sedimentary stone, all at once the strata of many times become present in one time. But simultaneity, in the painting "Two Ways," does not occur only once. It repeats itself, like the pulse of water from Sigurd Lewerentz's baptismal font. In an instant, the light gray tone spirals from the core to the periphery, while a horizontal line, generated by the absence of tone, conducts the eye to the edge of the picture where a movement and a counter movement point the way back. One returns, again and again, to an origin that is the same, in an event that hardly progresses.

Why do these artists make us conscious of an interval where motion occurs in an event that remains the same? What is the purpose of their disinterested measurement? And why do they ask us to consider recurrence rather than change. Perhaps it is an attempt to grasp some fragile permanence in the nature of existence, or maybe these things which have something to do with motion, simply ask a person to feel what it is to be present. Because, as Klee himself said, "... the moment is so fleeting." 2

Ad Reinhardt also imagined finding the aspects of existence which persist within phenomena that diminish with time. His "Black Paintings" suggest that waiting is fundamental to human being. They are waiting for a person, who is also willing to wait. For the hasty onlooker, the person in a hurry, there is no image, nothing at all, just black. But for the person who awaits, an image comes slowly to the surface from some unseen depth. This is not a mere technique, but a form that discloses a force that is invisible, intangible, and yet accessible to our consciousness. What is experienced in Reinhardt's painting is the immediate awareness of being present and a more permanent feeling of peace. Simply with paint and canvas, with some color, a basic shape, and a minimal differentiation of surface; with these purely physical means, he makes us wonder: what is life without waiting?

\section{TEMPORALITY AND PERMANENCE}

In his memoirs, the film maker Andrey Tarkovsky wrote, "Art affirms all that is best in man - hope, faith, love, beauty, prayer... What he dreams of, and what he hopes for... ${ }^{3}$ By setting timeless themes in temporal settings, by comparing an ideal of perfection to what is possible in actual existence, Tarkovsky heightened a person's sense of dissatisfaction with a present that "slips and vanishes like sand between the fingers ${ }^{4} \mathrm{His}$ touching images of the bond of love between a mother and her child, the disorientation of a man who longs for his home, or even the indescribable sense of well-being that a person can feel from the sound and sight of rain, are all feelings that emerge from the personal experi- 
ence of Tarkovsky himself, yet he understands the art of cinema to the extent that the memory of a mother's happiness, the emotional weight of nostalgia, or the joy of being alive in the world can be removed from the temporal limit of an individual's lifetime and situated in the permanence of something fundamentally human and timeless.

In Tarkovsky's films, the significance of the present is indistinguishable from memory. At the conclusion of "Andrey Rublyov," after three hours of black and white film, some colored images emerge from the ashes of a fire. Initially, what the camera captures is difficult to comprehend. First there is color, and then line and tone become equally dominant. After some time, it becomes clear that Tarkovsky is slowly scanning Rublyov's painting "Old Testament Trinity." By segmenting the surface of the painting and enlarging a detail, Tarkovsky takes an image that was formerly whole, and reconfigures it into a sequence of parts that occur in time, moving and changing - wrested out of the past in order to exist in the experience of the present.

By looking backward through a modern lens, is Tarkovsky revealing how present the medieval Rublyov actually is? From a modern perspective, the color, tonality, and line of this astonishing fragment from Rublyov's 'Trinity' appear complete and whole, in themselves and for themselves. Convincingly, this image reveals that until the time that it is no longer remembered, a work of art is never really behind us. What is constant and present, however, is more than the recollection of a work of art. This fragment of a surface from another lived time is significant to our time, because it is a poignant formulation of an ageless question: what is memory for?

\section{A PERPETUALLY PRESENT SEARCH}

Perhaps there is always something incomplete in a significant work of art that keeps it fresh and continually present. Maybe what is permanent in a work of art is not a particular formal aspect or an eternal value, but something else has been continually reconsidered. Maybe what appears modern in Rublyov and medieval in modern works is basic to art and fundamental for being - a perpetually present search for the beginning.

At the end of the twentieth century, after thousands of years and millions of hands have shaped what we consider to be art, can we still speak of beginning? Donald Judd thought so. In a lecture on Art and Architecture in 1983, he wrote "...the beginning always steps backwards so that rather than simply beginning, the beginning is a search for the beginning." 5

Understanding the beginning, like other understanding, seems to be inseparable from disinterested contemplation. In this regard, wanting to know the beginning is not merely beginning and moving forward, but more precisely, learning to contemplate the beginning; to uncover, and remain with, the fundamental ground of art.

In one of his last writings before he died two years ago, Donald Judd said something strange and challenging to us today. He wrote that "...color is almost brand new in the world." "There is a wonderful optimism in that statement, and even a hidden urgency; but the right kind of urgency. Judd suggests that there is much to be accomplished in the field of color, almost everything, in fact. "Color is almost brand new in the world." This matter of fact statement reminds us how much there is to know, how little time there is, and that the beginning remains for us to consider.

At the age of 87, after painting his series, 'Homage to the Square' for twenty five years, Josef Albers wrote, "I'm not done yet, I have to try new variations." 7 Albers remained at the beginning for the last twenty five years of his life, concentrating time in the study of color. Today, in a world where it appears that everything can take place faster, where change itself is a value, and progress seems certain, Albers patient search for the beginning is certainly strange, and almost a threat. Who has the time to learn the patience required to remain with a question, to perceive its vastness and dwell in its complexity? Why struggle for knowledge when the flow of information seems endless and accessible? And wasn't the beginning already considered a long time ago?

Because art is inclined toward what is fundamentally human, rather than what is temporally interesting, toward permanence rather than change, it resists the notion that progress is inevitable, either in human existence or in works of art. Regarding this issue, the Danish philosopher Søren Kierkegaard wrote, "no generation begins at any other point than the beginning... In this respect, every generation begins primitively, has no different task from that of the previous generation, nor does it get further, except in so far as the preceding generation shirked its task and deluded itself." ${ }^{8}$

\section{THE TIME OF CONTEMPLATION}

"The work of art," Jean-Paul Sartre wrote, "is a value because it is an appeal." " It is, he continued, "an exercise in generosity." ${ }^{10}$ A Donald Judd box is such an appeal. It begins with the experience of an isolated presence. Although these objects are absolutely immobile, they are not static, as long as there is a person who is willing to consider that the work is waiting for the assistance of their own imagination. In front of one of these boxes there is a suddenness, an allat-once-clarity, that separates in an instant, open and general space from limited and particular space. Despite their simple appearance, these boxes resist instantaneous apprehension. The space they make is rare, certain and still. By inviting a person to abide in this unusual and isolated calm, the boxes overcome their own immediacy by extending the duration of their presence. They are silent, and indicate that silence could be shared. They seem to hold open a present in which nothing arrives and nothing passes away. These empty objects, that simply contain and divide space, extend the moment in order to remind a person that time still matters when almost nothing happens.

A sign of spiritual poverty in contemporary existence is the way that the material and measurable aspects of western 
industrialized society have diminished a person's capacity to contemplate their world. Thirty years ago, the art critic Clement Greenberg wrote; I think a poor life is lived by anyone who doesn't regularly take time out to stand and gaze, or sit and listen, or touch, or smell, or brood, without any further end in mind, simply for the satisfaction gotten from that which is gazed at, listened to, touched, smelled, or brooded upon." "1

A work of art can permeate our being. It can gently take hold of a person and suggest what Jørn Utzon calls a, "magnificent tranquillity which has almost been forgotten." 12 In the art of building, a simple opening in a wall, can isolate a moment in the present, and help a person reflect upon who they are, where to begin, and what, if anything, is permanent in their temporal existence.

\section{NOTES}

' Klee, Felix, ed. The Diaries of Paul Klee 938, (1915), (Berkeley, California: University of California Press, 1964), 310.
${ }^{2}$ Klee, The Diaries of Paul Klee, 1081, (1917), 374.

${ }^{3}$ Tarkovsky, Andrey, Sculpting in Time, (Austin, Texas: University of Texas Press, 1989), 239.

4 Tarkovsky, Sculpting in Time, 58.

5 Judd, Donald, "Art and Architecture," Complete Writings 1975-1986, (Eindoven, Netherlands: Van Abbes Museum, 1987), 25.

' Judd, Donald, Josef Albers, (Köln, Germany: Distel-Verlag, 1991), 23.

"Albers, Josef, quoted in "Fifteen notes on Josef Albers," Josef Albers, (Köln,Germany: Galerie Karsten Greve, 1989), 8.

${ }^{8}$ Kierkegaard, Søren, quoted in Rollo May The Discovery of Being, (New York: W.W. Norton \& Company, 1986), 141.

${ }^{9}$ Sartre, Jean-Paul, What is Literature? (1947), (Gloucester, Mass.: Peter Smith, reprint 1978), 43.

10 Sartre, What is Literature?, 45.

"O'Brian, John, ed., Greenberg, Clement, The collected essays and criticism, Volume 4, Modernism with a Vengeance 1957. 1969, (Chicago, Illinois: University of Chicago Press, 1993), 75-76.

12 Utzon, Jørn, "Jørn Utzon on Architecture" Living Architecture, $8,(1989), 172$. 